\title{
Evaluación de biomasa de microalgas de la laguna Limoncocha como materia prima para la obtención de biocombustibles
}

\section{(Evaluation of Micro-Algae Biomass in the Limoncocha Lagoon as a Raw Material for the Production of Bio-fuels)}

\author{
Soledad Subía ${ }^{1}$, Jefferson Rubio ${ }^{1}$
}

\begin{abstract}
Resumen:
Se determinaron las mejores condiciones experimentales para la producción y evaluación de la biomasa de microalgas provenientes de Limoncocha con el objetivo de comprobar la factibilidad de uso en la obtención de biocombustibles. Se dio seguimiento a diferentes cultivos con el fin de obtener la cinética de crecimiento de las microalgas y establecer el rendimiento con el que se producen a escala de laboratorio controlando las diferentes variables que intervienen en dicho proceso. Una vez obtenida la biomasa en los fotobiorreactores se caracterizó para conocer su composición y contenido de lípidos. La productividad para el primer consorcio Vischeria/Scenedesmus sp fue de 0,088 $\mathrm{g} \mathrm{L}^{-1} \mathrm{dia}^{-1}$ alcanzando un total de 5030000 $\mathrm{cel} / \mathrm{mL}$ y para el segundo consorcio Chlorella/Monoraphidium Contortum sp fue de $0,091 \mathrm{~g} \mathrm{~L}^{-1} \mathrm{dia}^{-1}$ con un total de $5537636 \mathrm{cel} / \mathrm{mL}$. Para la composición lipídica por el método Soxhlet usando una mezcla de cloroformo/metanol como solventes, se obtuvieron resultados de $16 \%$ de lípidos totales para el consorcio de Vischeria/Scenedesmus sp y $42 \%$ para el consorcio de Chlorella/Monoraphidium Contortum sp.
\end{abstract}

Palabras clave: biocombustibles; consorcios; fotobiorreactores; lípidos; microalgas

\begin{abstract}
:
It was determined the best experimental conditions for the production and evaluation of microalgae biomass, which come from Limoncocha, for the purpose of proving the feasibility of use in biofuel acquisition. Different crops were monitored in order to obtain the growth kinetics of microalgae and establish the yield with which they are produced on a laboratory scale controlling the different variables that interfere in this process. Once the biomass was gotten in the photo bioreactors, it was characterized to know its composition and lipid content. The productivity for the first consortium Vischeria/Scenedesmus $s p$ was of $0,088 \mathrm{~g} \mathrm{~L}^{-1}$ day-1, which reached a total of $5030000 \mathrm{cel} / \mathrm{mL}$ and for the second consortium Chlorella/Monoraphidium Contortum $s p$ was of $0,091 \mathrm{~g} \mathrm{~L}^{-1}$ day-1 with a total of $5537636 \mathrm{cel} / \mathrm{mL}$. For the lipid composition through Soxhlet method by using a mixture of chloroform / methanol as solvents, the gotten results were from $16 \%$ out of the total lipids for Vischeria/Scenedesmus $s p$ consortium and $42 \%$ for Chlorella/Monoraphidium Contortum sp consortium.
\end{abstract}

Keywords: biofuels; consortium; lipids; photo bioreactors; microalgae.

\section{Introducción}

En la actualidad el área energética enfrenta dos importantes problemas: la reducción de las reservas petroleras y el aumento de la emisión de $\mathrm{CO}_{2}$ causante del cambio climático. Ambos resultados están relacionados directamente con la utilización de fuentes de energía derivadas de los combustibles fósiles. A partir de la revolución industrial los gases de efecto invernadero provenientes de los procesos industriales subieron drásticamente y solo hasta el siglo XX es cuando la comunidad científica les

\footnotetext{
${ }_{1}$ Universidad Internacional SEK, Quito, Ecuador (rodolfo.rubio@uisek.edu.ec)
} 
atribuye las alteraciones producidas en los ecosistemas y en la población humana (Ximhai, 2006).

Según el informe BP Statistical Review of World Energy de junio de 2016, para el año 2015 el consumo energético en el mundo aumentó el 0,97\%. Los combustibles fósiles continuaron siendo la principal fuente de energía a nivel mundial con una demanda del $86 \%$ y un $0,55 \%$ de crecimiento (López, De la Torre, \& González, 2016). Sin embargo, las proyecciones a futuro para los combustibles derivados del petróleo son cada vez menos prometedoras tomando en cuenta que los yacimientos restantes son más complicados de refinar por ser de crudo pesado y extrapesado, lo cual se refleja directamente en los costos de producción y en la rentabilidad de los mismos (Ximhai, 2006).

En el Ecuador la principal fuente en la generación de energía son los combustibles fósiles y para el año 2014 el $83 \%$ de la energía utilizada se derivó de los mismos, con el transporte como el mayor emisor de gases de efecto invernadero del sector (Ministerio Coordinador de Sectores Estratégicos, 2016). La economía del Ecuador depende fuertemente de los combustibles fósiles. Esta se sostiene mediante la exportación de crudo y la demanda de sus derivados los cuales superan los 7000 millones de barriles de petróleo según datos del Banco Central del Ecuador en el 2012 y 2013 (Salas, 2015).

La generación de nuevas energías alternativas que no estén ligadas a los combustibles fósiles resulta un desafío para la sociedad actual. En este contexto, son imprescindibles fuentes que sean eficientes para lograr competir con el mercado dominante del petróleo y que pueden satisfacer la demanda generada por los consumidores. Como consecuencia, se hace necesario la implementación de estudios, análisis y caracterización de nuevas materias primas y métodos para la obtención de combustibles sustentables que en un futuro puedan reducir la dependencia energética del petróleo y sus derivados (Salas, 2015).

\subsection{Biocombustibles}

Como consecuencia del aumento en los precios de los alimentos y los combustibles tradicionales, la noción sobre los biocombustibles comenzó a tomar fuerza a partir del 2008 como una alternativa para evitar el deterioro de los ecosistemas. Los biocombustibles de primera generación comprenden materias primas de origen agrícola, las cuales poseen un alto contenido de almidón, azúcares y aceites. Algunas de estas materias primas son la palma, soya, coco o semillas de girasol (Maciel, 2009). Adicionalmente se emplean como insumos a las grasas animales, aceites de desecho derivados de la cocción y restos de sólidos orgánicos (Maciel, 2009).

Materias primas agrícolas y forestales como la celulosa es empleada en la producción de biocombustibles de segunda generación, por ejemplo, el bagazo de la caña de azúcar, trigo, aserrín y hojas. Los procesos de producción de este tipo de biocombustibles tienen un mayor nivel de complejidad que los citados anteriormente, y con estos se logran producir etanol, metanol, gas de síntesis, biodiesel entre otros. Su ventaja principal se encuentra la reducción de materias primas destinadas principalmente al sector alimenticio (Maciel, 2009).

Finalmente los combustibles de tercera generación son obtenidos a partir de materias primas no destinadas a la alimentación, son de crecimiento rápido y se componen de biomoléculas de alta densidad energética denominados así "cultivos energéticos" (Maciel, 2009). La gran esperanza se enfoca sobre los estudios relacionados con este tipo de biocombustibles, en los cuales se aprovecha la biomasa producida por microorganismos fotosintéticos autótrofos o heterótrofos como son las microalgas. Estas materias primas además de facilitar el control de las de las emisiones de $\mathrm{CO}_{2}$ mediante la absorción y biofijación de este gas de efecto invernadero, aprovechan de mejor manera el uso del recurso hídrico (Grunewald, 2011). 


\subsection{Microalgas}

Las microalgas son organismos autótrofos unicelulares, coloniales y filamentosos los cuales pueden habitar en numerosos medios acuáticos y ecosistemas dentro del planeta Tierra. Presentan pigmentos fotosintéticos que permiten realizar una fotosíntesis aerobia. Es decir, son capaces de convertir la energía proveniente de la luz en energía química, siendo cuatro veces más eficientes que las plantas (Segoviano \& Islas, 2017). Son los organismos de crecimiento más rápido en la tierra, desarrollándose así en ambientes con $\mathrm{pH}$ y temperatura variables (Segoviano \& Islas, 2017).

Las microalgas son una fuente importante de biomoléculas y metabolitos que pueden ser aprovechados en un sinnúmero de aplicaciones con el fin de obtener un beneficio económico y generar energías alternativas (Malgas, 2013). Estos microorganismos están compuestos por lípidos, proteínas y carbohidratos y su contenido lipídico oscila entre 20 y 50 \% en peso seco (Colorado, Moreno, \& Pérez, 2013). Para su cultivo se necesita una menor superficie que otros cultivos agrícolas destinados al área energética (Ximhai, 2006).

El desarrollo de esta investigación aporta información acerca de las condiciones de cultivo, composición y rendimiento de la biomasa de consorcios de microalgas provenientes de Limoncocha en fotobiorreactores a escala de laboratorio para su posterior caracterización y aplicación en la producción de biocombustibles. Contribuye con la cinética de crecimiento de las microalgas mediante conteo celular y densidad óptica, la productividad de biomasa seca en los fotobiorreactores y los métodos de caracterización en la cuantificación de lípidos totales y perfil lipídico. La realización de este trabajo busca generar soluciones para la disminución de los impactos generados por los combustibles fósiles en los ecosistemas y de esta forma contribuir al mejoramiento de esta problemática.

\section{Metodología}

\section{1. Área de estudio y muestreo de cepas}

La reserva de Limoncocha está ubicada a $210 \mathrm{~km}$ al este de Quito, en la provincia del Napo, cantón Shushufindi, parroquia de Limoncocha (Ulloa, 1988). Los puntos de muestreo (Figura 1) fueron obtenidos de los afluentes y efluentes (Pishira y Playa Yacu) ya que la unión de estos ríos con la laguna provoca una mayor proliferación de microalgas debido a la cantidad de nutrientes vegetales presentes en el lugar, estos son:

- Punto 1: El Caño

- Punto 2: Desembocadura del Pishira

- Punto 3: Desembocadura de Playa Yacu

- Punto 4: Zona Profunda

- Punto 5: Muelle

\subsection{Medio de cultivo} Bold).

Para la cinética de crecimiento celular se preparó el medio BBM (Medio Basal de

\subsection{Condiciones de cultivo}

\subsubsection{Cultivo inicial}

Para el primer batch se inocularon $100 \mathrm{~mL}$ en cada uno de los fotobiorreactores con un número inicial de $15157 \mathrm{cel} / \mathrm{mL}$ de las cepas Vischeria/Scenedesmus sp. El período de crecimiento para este consorcio fue de 12 días. 
En el segundo batch de microalgas se inocularon $50 \mathrm{~mL}$ en cada uno de los fotobiorreactores con un número inicial de $2342 \mathrm{cel} / \mathrm{mL}$ de las cepas Chlorella/Monoraphidium Contortum sp. El período de crecimiento para este consorcio fue de 15 días.

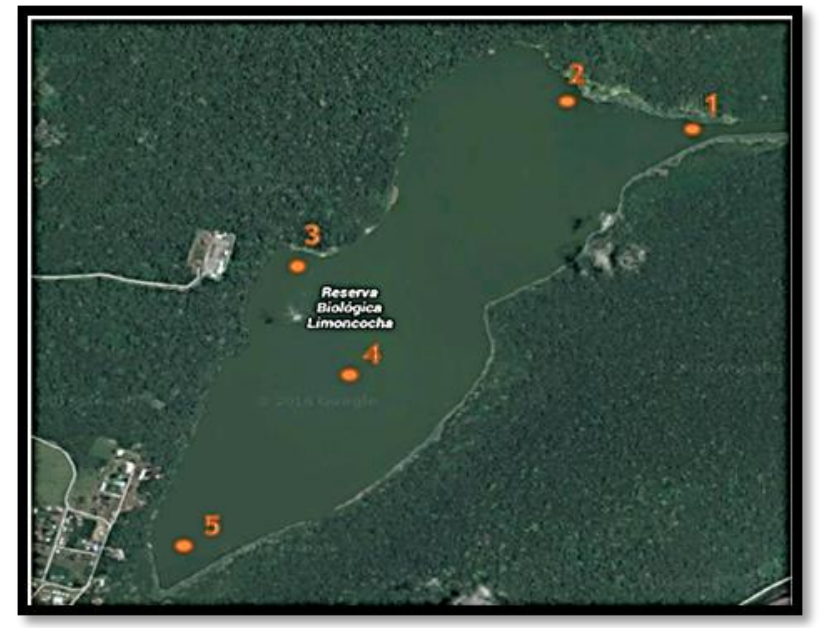

Figura 1. Mapa de la reserva biológica Limoncocha. Fuente: (MAE, 2010)

\subsubsection{Fotobiorreactores}

Cilindros de vidrio, transparentes y lisos con un volumen total de $4000 \mathrm{cc}$ los cuales contenían el medio BBM para el crecimiento de las microalgas. Se implementaron un total de 10 fotobiorreactores por cada consorcio de microalgas bajo las mismas condiciones de cultivo (Tabla 1).

\subsubsection{Iluminación}

La energía lumínica proporcionada fue artificial mediante lámparas LED las cuales han determinado ser la fuente más eficiente y económica ya que emiten más del $98 \%$ de su luz entre 600 y $700 \mathrm{~nm}$ (Malgas, 2013). Se diseñaron estructuras de madera para el soporte de un total de 9 lámparas que funcionaron en un fotoperíodo de 24 horas.

\subsubsection{Temperatura}

Para el control de temperatura se usó un calefactor de aceite modelo CYS30-7 con una potencia de $1,5 \mathrm{~kW}$ para mantener un rango estable durante el período de crecimiento celular. Se conservó una variación de $\pm 2{ }^{\circ} \mathrm{C}$ en el proceso verificando este parámetro mediante un sensor de temperatura.

\subsubsection{Aireación}

Se desarrolló un sistema de aireación para la homogenización y oxigenación de los cultivos. Se utilizaron mangueras, alambre de acero inoxidable y un compresor TIGER modelo JYK50 de $50 \mathrm{~L}$ con una tasa de aireación de 4,2 L min ${ }^{-1}$ reactor ${ }^{-1}$ con el fin de evitar la sedimentación de la biomasa en las paredes de los fotobiorreactores y asegurar la distribución homogénea de los nutrientes presentes en el medio BBM.

Tabla 1. Condiciones de cultivo de las cepas en estudio

\begin{tabular}{|c|c|}
\hline lluminación & Lámparas LED's \\
\hline Temperatura & $28 \pm 2^{\circ} \mathrm{C}$ \\
\hline pH & 6,6 \\
\hline Aireación & Constante \\
\hline
\end{tabular}




\subsection{Conteo celular}

\subsubsection{Método 1: microscopio y cámara de Neubauer}

Para el conteo celular por método directo se usó la cámara de Neubauer (Figura 2), la cual es una placa de cristal con forma similar al de un portaobjetos. Se deben contar el número de células presentes en los cuadrantes de color rojo considerando que para esto se enumeran las células de los cuadrados más pequeños realizándolo en forma de zigzag (Bastidas, 2011). Los conteos se realizaron cada 24 horas y se realizó la identificación de las diferentes cepas mediante observación en el microscopio. Para el conteo celular se tomaron muestras diarias en 4 de los 10 cultivos para ambos consorcios.

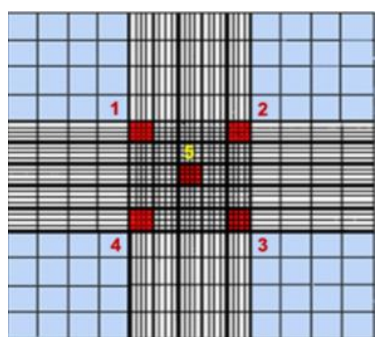

Figura 2. Detalle de la rejilla de una cámara de Neubauer. Fuente: (Bastidas, 2011).

La Ecuación 1 (Bastidas, 2011), presenta la fórmula para sacar la concentración de células por mililitro.

$$
\text { Concentración }=\frac{\text { Total células contadas } \mathrm{x} 10.000}{\text { Número de cuadrados } \mathrm{x} \text { dilución }}
$$

\subsubsection{Método 2: densidad óptica por espectrofotometría UV-Visible}

Para la aplicación de este método matemático para la generación de líneas en gráficos se establecieron curvas de correlación lineal entre dos variables, en este caso la concentración celular obtenida mediante conteo directo y la absorbancia. Se midió dicho valor a $675 \mathrm{~nm}$ siendo este valor cercano al pico de absorción de la clorofila (Arredondo \& Voltolina, 2007).

\subsubsection{Obtención de biomasa seca}

Para la recolección de la biomasa se utilizó el método de centrifugación a 3000 rpm durante 10 minutos por litro de cultivo. Se empleó un centrifuga modelo K de International Equipment Co. de 1 litro de capacidad y $3 / 4$ HP para recolectar la biomasa separada en pellets, las que posteriormente pasaron secado final en la estufa durante 1 hora a $105^{\circ} \mathrm{C}$.

\subsubsection{Pretratamiento de la biomasa}

Para realizar la disrupción celular de los consorcios de microalgas Vischeria/Scenedesmus sp y Chlorella/Monoraphidium Contortum sp se re suspendió la biomasa seca en una solución buffer de extracción para posteriormente congelar a $-80^{\circ} \mathrm{C}$ durante un período de 24 horas.

\subsubsection{Extracción y cuantificación de lípidos}

La extracción de lípidos se realizó mediante el método Soxhlet. Para la elección del solvente se buscó el mejor rendimiento del proceso por lo tanto, se utilizó una mezcla 
cloroformo (99.4\%): metanol (99\%) (1:2) con el objetivo de captar los diferentes tipos de lípidos presentes en la biomasa de microalgas (García, 2011). Se realizaron ensayos por duplicado.

Se tomaron 5 gramos de biomasa seca de los diferentes consorcios añadiendo 300 $\mathrm{mL}$ la mezcla binaria de solventes en el matraz. El proceso de extracción se completó en 8 horas y se recuperó el solvente mediante destilación simple en 4 horas. Finalmente se pesaron los balones con grasa para determinar el contenido lípido por diferencia con la Ecuación 2.

$$
\% \text { grasa cruda }=\frac{m 2-m 1}{m * 100}
$$

Donde:

$$
\begin{aligned}
& \mathrm{m} \text { : peso de la muestra } \\
& \mathrm{m} 1 \text { : tara del matraz solo } \\
& \mathrm{m} 2 \text { : peso matraz con grasa }
\end{aligned}
$$

\subsubsection{Perfil lipídico}

Para el perfil lipídico se utilizó el método de cromatografía en capa fina (T.L.C), se usaron placas preparadas de sílica gel marca MERCK y una solución de ácido bórico para su activación en la estufa.

Para la preparación de la muestra se tomó 10 miligramos de biomasa de ambos consorcios de microalgas y se agregó $300 \mu \mathrm{L}$ de cloroformo (99.4\%): metanol (99\%) (2:1). Se procedió a centrifugar las muestras durante 5 minutos, se recolectó el sobrenadante y se realizó el mismo procedimiento dos veces con el pellet de biomasa restante hasta sumar un volumen total de $1 \mathrm{~mL}$ de sobrenadante transvasado (Antequera \& Martinez, 2006).

Se sembró la muestra a $1 \mathrm{~cm}$ del borde inferior en fracciones de $2 \mu \mathrm{L}$ hasta llegar a concentrar la muestra a $100 \mu \mathrm{L}$ respetando el intervalo de secado, (M1) para Vischeria/Scenedesmus sp y (M2) para Chlorella/Monoraphidium Contortum sp. Se procedió a la preparación del solvente o fase móvil de la T.L.C con una mezcla de cloroformo/metanol/agua/ hidróxido de amonio (70:30:3:2) (Antequera \& Martinez, 2006).

Como marcador para el perfil lipídico se utilizó lecitina de soya (M) la cual tiene en su composición fosfatidilserina, fofatildicolina, fosfatidilinositol y fosfatidiletanolamina con $\mathrm{Rf}$ (Ratio of Front) de 0,13, 0,68, 0,20 y 0,75 respectivamente (ver Ecuación 3) coincidiendo con datos propuestos en la literatura (Tamargo-Santos, 2011).

$$
R f=\frac{\text { Distancia de la muestra desde el origen }}{\text { Distancia del eluyente desde el origen }}
$$

(Sánchez, 2010)

\section{Resultados y discusión}

La Figura 4 muestra la cinética de crecimiento para el consorcio Vischeria/Scenedesmus $s p$ las condiciones de cultivo favorecieron el crecimiento de la cepa Vischeria sp estableciendo mediante conteo celular el crecimiento exponencial de la misma. Por otra parte, la cepa Scenedesmus sp a diferencia de la cepa anterior en las mismas condiciones de cultivo no entró en fase exponencial de crecimiento. En un período de cultivo de 12 días se obtuvieron un total de $5030000 \mathrm{cel} / \mathrm{mL}$.

La Figura 5 muestra la cinética de crecimiento consorcio de microalgas Chlorella/Monoraphidium Contortum $s p$ las condiciones de cultivo favorecieron el crecimiento de la cepa Monoraphidium Contortum sp estableciendo mediante conteo celular el crecimiento exponencial de la misma. Por otra parte, la cepa Chlorella $s p$ a 
diferencia de la cepa anterior en las mismas condiciones de cultivo no entró en fase exponencial de crecimiento. En un período de cultivo de 15 días se obtuvieron un total de $5537636 \mathrm{cel} / \mathrm{mL}$

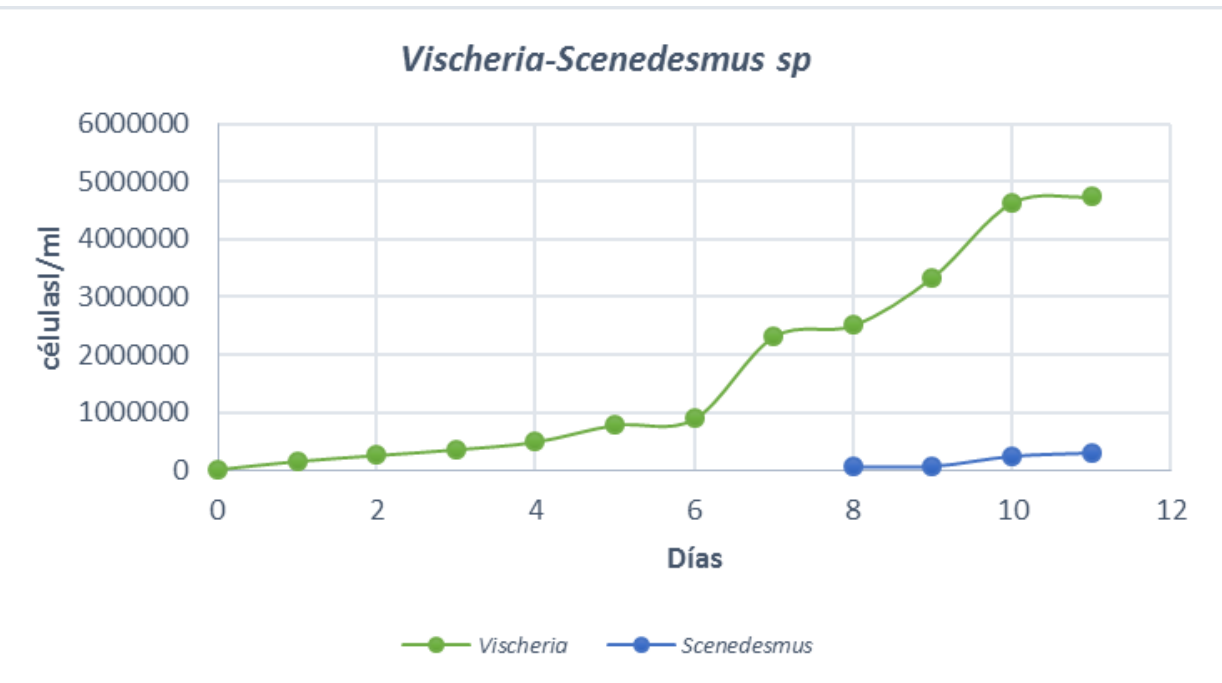

Figura 4. Cinética de crecimiento del consorcio Vischeria/Scenedesmus sp en medio BBM mediante conteo celular

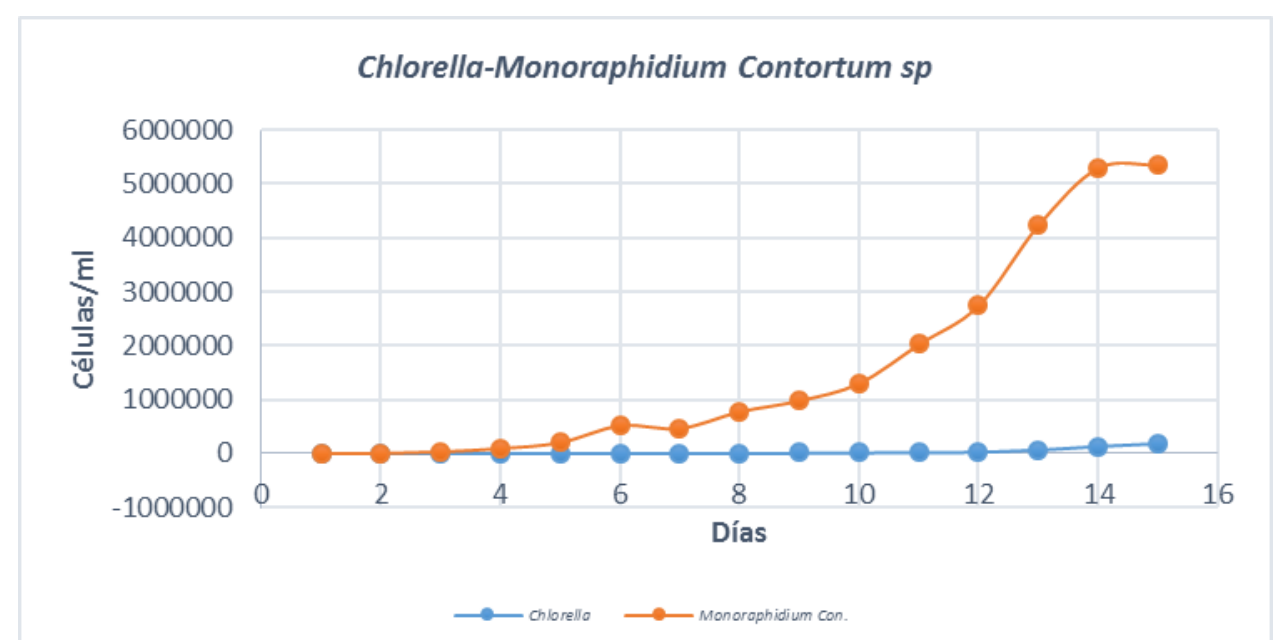

Figura 5. Cinética de crecimiento del consorcio Chlorella/Monoraphidium Contortum sp en medio BBM mediante conteo celular

\subsection{Densidad óptica}

Para la concentración celular mediante el método indirecto de densidad óptica la (Figura 6) sugiere que el método no se ajusta de forma precisa dando un valor en la correlación de 0,90 para el primer consorcio de microalgas Vischeria/Scenedesmus sp.

Para la concentración celular mediante el método indirecto de densidad óptica la (Figura 7) sugiere que el método no se ajusta de forma precisa dando un valor en la correlación de 0,91 para el segundo consorcio de microalgas Chlorella/Monoraphidium Contortum sp.

La concentración de células puede ser estimada de forma indirecta mediante la densidad óptica, sin embargo, la precisión de los resultados es menor que con el recuento directo. Lo que se busca con la aplicación de este método es una evaluación rápida del número celular en los cultivos. Si bien es cierto las correlaciones están por arriba del 0,90 en ambos consorcios, para cultivos puros los resultados se acercan a valores de 0,98 y 0,99 (Lu, Yang, Zhu, \& Pan, 2017). Es decir, el método está sujeto a 
ciertos errores por lo que se debe priorizar la utilización del microscopio y cámara de Neubauer si no se tiene un cultivo axénico.

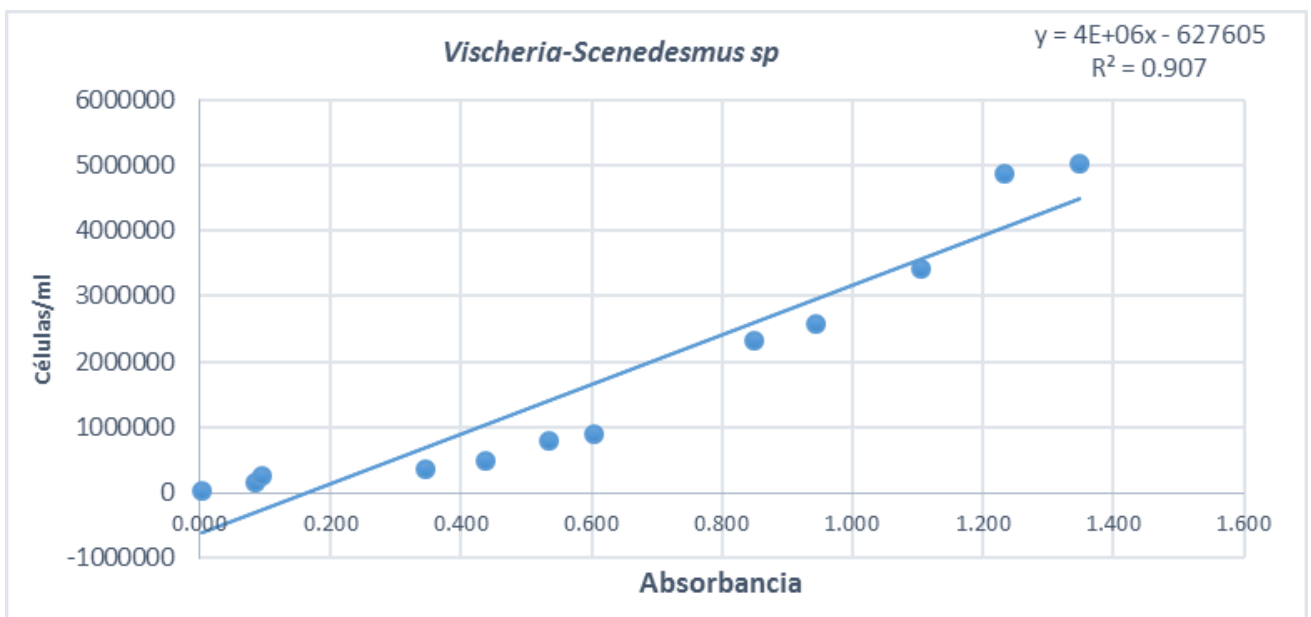

Figura 6. Correlación de la concentración celular versus la densidad óptica para Vischeria/Scenedesmus sp.

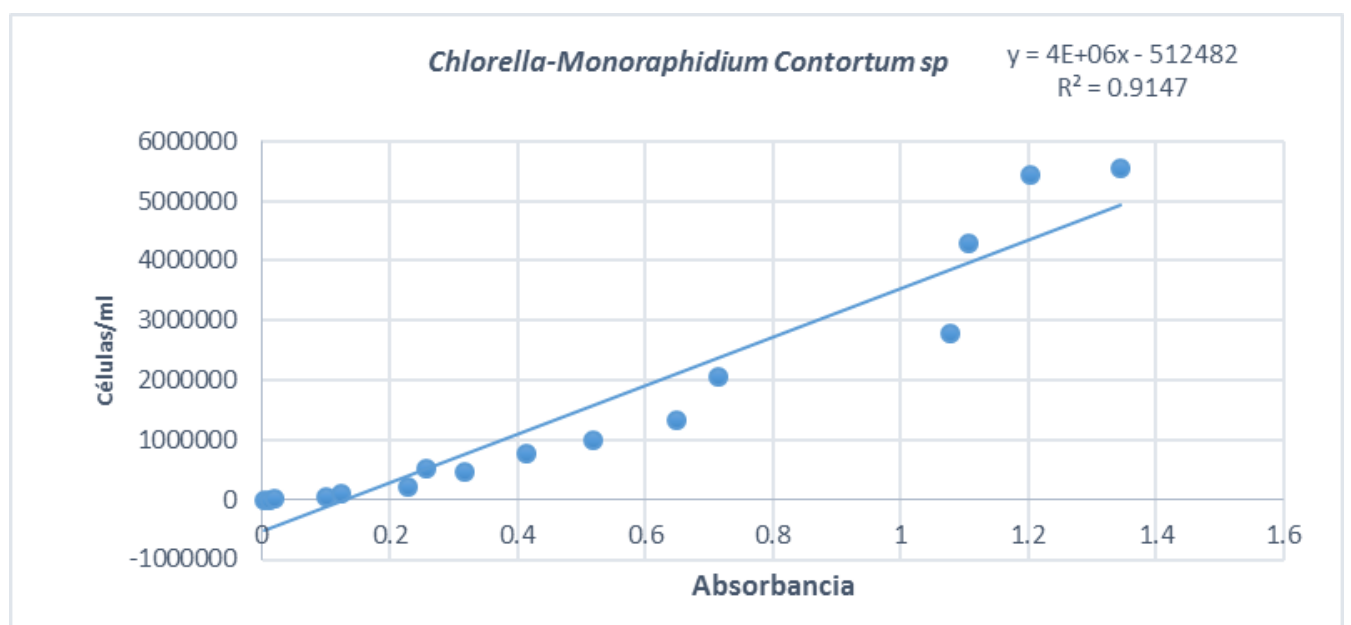

Figura 7. Correlación de la concentración celular versus la densidad óptica para Chlorella/Monoraphidium Contortum sp.

\subsection{Productividad de biomasa seca}

La productividad media de biomasa seca en los fotobiorreactores para el primer consorcio de microalgas fue de $0,088 \mathrm{~g} \mathrm{~L}^{-1} \mathrm{dia}^{-1}$ (Tabla 2). Se obtuvieron un total de 28,48 gramos de biomasa seca en los 10 cultivos para su posterior caracterización en un período de 12 días.

La productividad media de biomasa seca en los fotobiorreactores para el segundo consorcio de microalgas fue de $0,091 \mathrm{~g} \mathrm{~L}^{-1} \mathrm{dia}^{-1}$ (Tabla 3). Se obtuvieron un total de 31,53 gramos de biomasa seca en los 10 cultivos para su posterior caracterización en un período de 15 días.

En comparación con otros estudios Berthold (2016) expone que bajo condiciones óptimas de luz y temperatura algunas especies de microalgas son capaces de crecer a tasas de 0,026 $\mathrm{g} \mathrm{L}^{-1} \mathrm{dia}^{-1}$ es decir, que la productividad en ambos batch es alta. 


\subsection{Cuantificación de lípidos}

Se determinó que el porcentaje de lípidos totales contenidos en el primer consorcio de microalgas Vischeria/Scenedesmus sp es de 16\% con un período de extracción y recuperación de 12 horas en una mezcla binaria de solvente cloroformo: metanol (1:2) (Tabla 4, y Tabla 5).

Tabla 2. Productividad biomasa seca consorcio Vischeria/Scenedesmus sp.

\begin{tabular}{|c|c|c|c|c|c|}
\hline Cultivo & Productividad $\left(\mathrm{g} \mathrm{L}^{-1} \mathrm{dia}^{-1}\right)$ & $\bar{X}\left(g^{-1}\right.$ dia- $\left.^{-1}\right)$ & $|x-\bar{x}| 2$ & $\sum|x-\bar{x}| 2$ & $\mathbf{s}$ \\
\hline Cultivo 2 & 0,11 & \multirow{4}{*}{0,088} & 0,00065 & \multirow{4}{*}{0,0014} & \multirow{4}{*}{0,019} \\
\hline Cultivo 3 & 0,06 & & 0,00065 & & \\
\hline Cultivo 6 & 0,10 & & 0,00006 & & \\
\hline Cultivo 9 & 0,08 & & 0,00006 & & \\
\hline
\end{tabular}

Tabla 3. Productividad biomasa seca consorcio Chlorella/Monoraphidium Contortum sp.

\begin{tabular}{|c|c|c|c|c|c|}
\hline Cultivo & Productividad $\left(\mathrm{g} \mathrm{L}^{-1} \mathrm{dia}^{-1}\right)$ & $\bar{X}\left(g ~ L^{-1}\right.$ dia- $\left.{ }^{-1}\right)$ & $\left|x-x^{-}\right| 2$ & $\sum\left|x-x^{-}\right| 2$ & s \\
\hline Cultivo 1 & 0,10 & \multirow{4}{*}{0,091} & 0,00008 & \multirow{4}{*}{0,0011} & \multirow{4}{*}{0,017} \\
\hline Cultivo 3 & 0,09 & & 0,00001 & & \\
\hline Cultivo 6 & 0,11 & & 0,00024 & & \\
\hline Cultivo 8 & 0,06 & & 0,00077 & & \\
\hline
\end{tabular}

El porcentaje de lípidos totales contenidos en el segundo consorcio de microalgas Chlorella/Monoraphidium Contortum sp es de $42 \%$ con un período de extracción y recuperación de 12 horas en una mezcla binaria de solvente cloroformo: metanol (1:2) (Tabla 6 y Tabla 7 )

Tabla 4. Cuantificación de lípidos totales consorcio Vischeria/Scenedesmus sp.

\begin{tabular}{|l|l|}
\hline $\mathbf{m}:$ peso de la muestra g & $\mathbf{5 , 0 0}$ \\
\hline $\mathbf{m} 1:$ tara del matraz solo $\mathbf{g}$ & 180,5498 \\
\hline $\mathbf{m} 2:$ peso matraz con grasa & 181,3538 \\
\hline $\mathbf{g}$ & $\mathbf{1 6} \%$ \\
\hline Lípidos totales &
\end{tabular}

Tabla 5. Producción diaria de lípidos consorcio Vischeria/Scenedesmus $s p$.

\begin{tabular}{|c|c|c|c|}
\hline $\mathbf{N}^{\circ}$ & $\mathbf{g}^{\star} \mathrm{L}^{-1}$ & $\mathrm{~g} \mathrm{~L}^{-1 *} \mathrm{dí}^{-1}$ & lípidos $\mathrm{g} \mathrm{L}^{-1 \star}$ día $^{-1}$ \\
\hline Cultivo 2 & 1,36 & 0,11 & 0,018 \\
\hline Cultivo 3 & 0,75 & 0,06 & 0,010 \\
\hline Cultivo 6 & 1,15 & 0,09 & 0,015 \\
\hline Cultivo 9 & 0,96 & 0,08 & 0,012 \\
\hline
\end{tabular}

Tabla 6. Cuantificación de lípidos totales consorcio Chlorella/Monoraphidium Contortum sp.
$\mathrm{m}$ : peso de la muestra $\mathrm{g} \quad \mathbf{5 , 0 0}$
m1: tara del matraz solo g 189,0063
m2: peso matraz con grasa 191,1002
g

\begin{tabular}{l|l} 
Lípidos totales & $42 \%$
\end{tabular}

Tabla 7. Producción diaria de lípidos consorcio Chlorella/Monoraphidium Contortum sp.

\begin{tabular}{|c|c|c|c|}
\hline $\mathbf{N}^{\circ}$ & $g^{\star} L^{-1}$ & $\mathrm{~g} \mathrm{~L}^{-1 \star}$ día $^{-1}$ & lípidos $\mathrm{g} \mathrm{L}^{-1 *}$ día $^{-1}$ \\
\hline Cultivo 1 & 1,50 & 0,12 & 0,020 \\
\hline Cultivo 3 & 1,42 & 0,11 & 0,018 \\
\hline Cultivo 6 & 1,60 & 0,13 & 0,021 \\
\hline Cultivo 8 & 0,95 & 0,07 & 0,012 \\
\hline
\end{tabular}


Según Tejeda-Benítez et al. (2015) la cepa con mayor contenido lipídico es Chlorella $s p$ con un valor de $40.23 \%$. La viabilidad para la producción de biodiesel depende de cuánto de la biomasa corresponde a estos compuestos, por lo tanto, el consorcio Chlorella/Monoraphidium Contortum sp tendría mejores rendimientos en la producción de biocombustibles debido a su alto contenido de lípidos totales.

\subsection{Perfil lipídico}

Para el perfil lipídico (Tabla 8), la muestra para el primer consorcio formado por las cepas Vischeria/Scenedesmus sp (M1) la presencia de fosfatidilinositol y fosfatidiletanolamina con $\mathrm{Rf}$ de 0,25 y 0,87 respectivamente. Para (M2) correspondiente al segundo consorcio formado por Chlorella/Monoraphidium Contortum sp se puede observar la presencia de fosfatidilinositol, fosfatidilcolina, fosfatidiletanolamina con Rf de $0,23,0,73$ y 0,85 respectivamente (Figura 8 ).

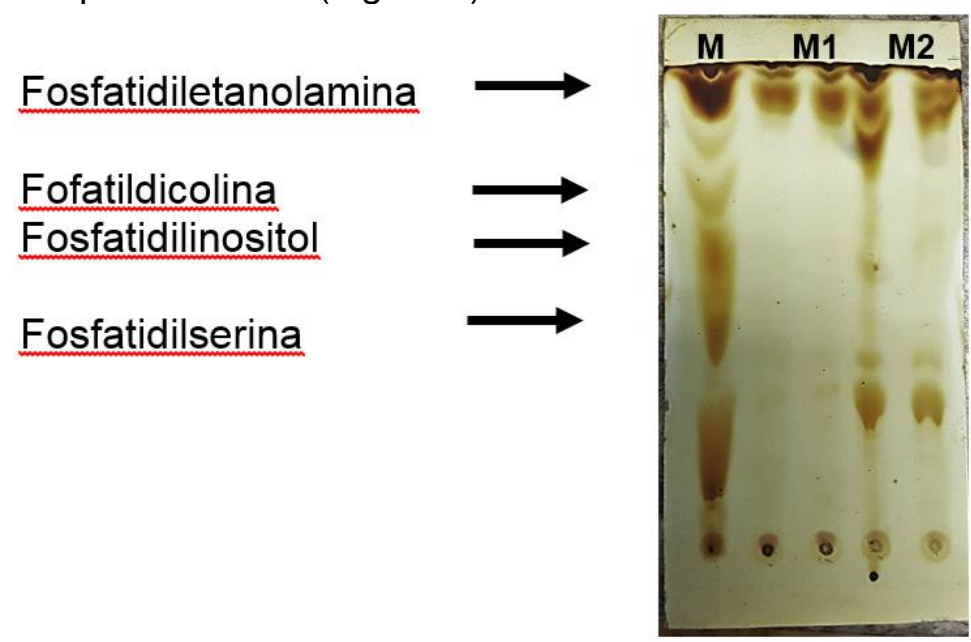

Figura 8. Identificación de compuestos lipídicos empleando como marcador lecitina de soya

Tabla 8. Datos de los compuestos lipídicos relacionados por Cromatografía en Capa Fina

\begin{tabular}{|l|l|l|l|}
\hline & Rf & M1 (Primer consorcio) & M2 (Segundo consorcio) \\
\hline Fosfatidilserina & 0,13 & - & - \\
\hline Fosfatidilinositol & 0,20 & 0,25 & 0,23 \\
\hline Fosfatidilcolina & 0,68 & - & 0,73 \\
\hline Fosfatidiletanolamina & 0,80 & 0,83 & 0,82 \\
\hline
\end{tabular}

\section{Conclusiones}

Las condiciones de cultivo en medio BBM, pH 6,6, luz artificial continua (lámparas LED's) y aireación constante favorecen el crecimiento exponencial de la cepa Vischeria $s p$ en el primer consorcio logrando valores de $5030000 \mathrm{cel} / \mathrm{mL}$ y de la cepa Monoraphidium Contortum sp para el segundo consorcio con valores de $5537636 \mathrm{cel} / \mathrm{mL}$.

El método por densidad óptica está sujeto a errores relacionados con la toma de muestra o calibración del equipo o pureza del cultivo, por lo tanto, es necesario la aplicación de métodos directos para saber con exactitud el número de células presentes en los diferentes cultivos.

En relación con la productividad de biomasa microalgas la implementación de condiciones de cultivo a escala de laboratorio produce buenos rendimientos en el crecimiento celular de ambos consorcios de microalgas.

En la extracción de lípidos totales mediante el método Soxhlet se determinó que el segundo consorcio compuesto por Chlorella/Monoraphidium Contortum sp tiene mejores rendimientos en la producción de biocombustibles ya que la eficiencia del proceso depende del contenido lipídico presente en la biomasa. 
Mediante la cromatografía en capa fina T.L.C es posible la identificación de lípidos anfipáticos como son los fosfolípidos contenidos en la biomasa de consorcios de microalgas, usando lecitina de soya como indicador y una fase móvil de cloroformo/metanol/agua/hidróxido de amonio.

\section{Bibliografía}

Antequera, Y., \& Martinez, E. (2006). Informe de Supul Fosfolípidos.

Arredondo, B., \& Voltolina, D. (2007). Concentración, recuento celular y tasa de crecimiento.

Bastidas, O. (2011). Conteo Celular con Hematocitómetro. Technical Note-Neubauer Chamber Cell Counting, 1-6.

Berthold, E. D. (2016). Enhancing Algal Biomass and Lipid Production through Bacterial and Fungal Co-Culture. https://doi.org/10.25148/etd.FIDC000792

Colorado, M., Moreno, D., \& Pérez, J. (2013). Desarrollo , producción y beneficio ambiental de la producción de microalgas. Ambiente y Desarrollo, 17(32), 113-126.

García, J. (2011). Comparación de métodos de extracción de aceite de microalgas a escala laboratorio para la producción de biodiesel.

Grunewald, C. fuentes. (2011). Uso De Microalgas Marinas Para La Producción De Biodiesel En Chile, 107-113. Retrieved from http://digital.csic.es/handle $/ 10261 / 52848$

López, J., De la Torre, A., \& González, A. (2016). Artículo panorama energético y energía nuclear a octubre de 2016, 62-68.

Lu, L., Yang, G., Zhu, B., \& Pan, K. (2017). A comparative study on three quantitating methods of microalgal biomass. Indian Journal of Geo Marine Sciences, 46(11), 2265-2272. Retrieved from http://nopr.niscair.res.in/bitstream/123456789/42970 /1/IJMS 46\%2811\%29 2265-2272.pdf

Maciel, C. Á. (2009). Biocombustibles: desarrollo histórico-tecnológico:mercados actuales y comercio internacional, 63-89.

Madigan, M., Martinko, J., \& Parker, J. (2003). Brock. Biología de los microorganismos.

Malgas. (2013). Aplicaciones de las microalgas: estado de la técnica. Journal of Chemical Information and Modeling, 69. https://doi.org/10.1017/CBO9781107415324.004

Ministerio Coordinador de Sectores Estratégicos. (2016). Agenda Nacional de Energía 2016-2040, $80 . \quad$ Retrieved from http://biblioteca.olade.org/opactmpl/Documentos/cg00362.pdf

Salas, M. (2015). Perfil lipídico de microalgas antárticas recolectadas en febrero 2013 en el archipiélago Schetland.

Sánchez, G. (2010). Comprobación de la actividad tintorera en fibras orgánicas y sintéticas.

Segoviano, A., \& Islas, E. A. (2017). Estudio de la cinética de crecimiento de Phormidium $\mathrm{sp}$ en función de la concentración de nitrógeno para su aprovechamiento biotecnológico. Aguilera, (1), 149-153.

Tamargo-Santos, B. (2011). Obtención de fosfolípidos a partir de la lecitina de soya (Glicine max L), para usos biomédicos, (June 2017).

Tejeda-Benítez, L., Henao-Argumedo, C., Alvear-Alayón, M., \& Castillo-Saldarriaga. (2015). Caracterización y perfil lipídico de aceites de microalgas Characterization and lipid profile of oil from microalgae Caracterização e perfil lipídico de azeites de microalgas, 24(39), 43-54.

Ulloa, R. (1988). Plan de Manejo Reserva Biológica Limoncocha, 1-101.

Ximhai, R. (2006). Producción de biocombustibles a partir de microalgas. Crisis, 2, 319_ 341. 